\title{
Necessity to Develop a Tool to Evaluate Activity of Daily Living for Electric Powered Indoor/ Outdoor Chair Users
}

\author{
Jiwon Lee, MD ${ }^{1}$, Jae Kuk Lim, MD ${ }^{1}$, Min Jun Lee, MD $^{1}$, Yoon-Sik Jo, MD², \\ Jae Sung Park, $\mathrm{MD}^{3}$, Jong Moon Kim, $\mathrm{MD}^{1}$, Shin Kyoung Kim, $\mathrm{MD}^{1}$ \\ Departments of ${ }^{1}$ Rehabilitation Medicine, ${ }^{2}$ Neurology, and ${ }^{3}$ Neurosurgery, \\ Konkuk University School of Medicine, Chungju, Korea
}

Objective To evaluate changes in activity of daily living before and after provision of electric-powered indoor/ outdoor chair (EPIOC), discuss problems of current activities of daily living (ADL) evaluating tools for EPIOC users, and provide preliminary data to develop ADL evaluation tool for EPIOC user.

Methods A total of 70 users who were prescribed EPIOC and had been using for more than 1 year were recruited in this study. Before and after provision of EPIOC, MBI and FIM scores were measured and a questionnaire consisting of six categories (general socioeconomic states, currently using state, whether EPIOC was helpful for social participation and occupational chances, psychiatric influences, self-reported degrees of independency, and barriers of using EPIOC) was used.

Results No difference in MBI scores before and after provision of EPIOC was observed. However, the wheelchair ambulation category showed a significant difference. While motor FIM was not significantly different from MBI, FIM score were significantly $(\mathrm{p}<0.05)$ higher than MBI. For questions regarding social participation frequency, helpfulness of EPIOC on confidence, refreshing patients' emotions and self-reported degrees of independence, all of them showed positive responses. Especially, EPIOC users' self-reported degree of independency showed favorable results. There was discrepancy in MBI or FIM measured by physicians.

Conclusion Our study showed that there was a gap between the existing ADL evaluation tool and the ADL level that EPIOC users were actually feeling. Thus, it is necessary to develop an evaluation tool specifically for EPIOC.

Keywords Activities of daily living, Disability evaluation, Self-help devices, Wheelchairs

Received June 10, 2014; Accepted September 11, 2014

Corresponding author: Shin Kyoung Kim

Department Rehabilitation Medicine, Konkuk University School of Medicine, 82 Gugwon-daero, Chungju 380-704, Korea

Tel: +82-43-840-8890, Fax: +82-43-851-3402, E-mail: kimnerve@hanmail.net

(c) This is an open-access article distributed under the terms of the Creative Commons Attribution Non-Commercial License (http://creativecommons. org/licenses/by-nc/3.0) which permits unrestricted noncommercial use, distribution, and reproduction in any medium, provided the original work is properly cited.

Copyright $\odot 2015$ by Korean Academy of Rehabilitation Medicine

\section{INTRODUCTION}

According to the UN Convention on the Rights of Persons with Disabilities, people with functional impairments should have the opportunity to experience personal autonomy, live independent lives, and participate fully in all aspects of life on an equal basis with others. An aid can play an important role in reaching this goal in 
everyday life by compensating for the persons' functional impairments [1].

In the same context, the demand for using wheelchairs is rising because the number of aged population and acquired disabilities is increasing. Especially, electric-powered wheelchair/scooter users are growing rapidly because of improved welfare policy and gentrified demand for ambulatory assistive devices [2]. According to 2011 Korean National Health Insurance Statistical Yearbook, approximately twelve thousand electric powered indoor/ outdoor chairs (EPIOCs) have been provided to disabled persons yearly. The total number of EPIOCs provided is estimated at about eighty thousand, including those provided by National Health Insurance and purchased personally.

A wheelchair not only serves as a fundamental device for indoor and outdoor ambulation, it also enhances ADL and community integration of those who cannot walk independently [3]. Powered wheelchairs are used due to the following reasons: poor muscular endurance, severe musculoskeletal pain, upper extremities range of motion limitation, and coordination disorder to the extent of having difficulty in using manual wheelchairs [4]. EPIOCs can enable long distance trip without effortful propelling push rim. It greatly enhances ADL and social participation for disabled persons who cannot control manual wheelchair due to diverse causes [5,6].

In Korea, EPIOCs have been covered by National Health Insurance since April 2005 for appropriate physically disabled persons who have amputation or range of motion limitation, spinal cord injury, brain lesion, or other severe systemic diseases. Although there are more detailed prescription criteria for each type of disability, the broad principles for prescription of EPIOC were 1) those who cannot walk independently over $100 \mathrm{~m}$ with impaired upper extremities function, 2) those who are measured below fair grade of upper extremities on manual muscle test for electric-powered wheelchair and those who are measured over good grade for electric-powered scooter, 3) those who score over 24 in Mini-Mental State Examination, and 4) those who score appropriate Modified Barthel Index (MBI). As shown above, the criteria for prescription of EPIOC is somewhat vague and inappropriate to reflect the actual conditions of disabilities. It can be subjective by the examiner. Moreover, the adequacy of EIPOC for every patient is formally inspected within one month after purchasing EPIOC. However, it is practically difficult to continuously follow-up on functional outcome of using EIPOC. Even if long-term follow-up is capable, a MBI is somewhat inappropriate as an evaluation tool for ADL [7]. This is because MBI is too broad to evaluate specifically EPIOC user's ADL and absent items, such as social activities and psychiatric evaluation.

In the view of rehabilitation, measuring the independency of patients' functional ability at home and in the community is essential. In other literatures, attempts to develop tools for functional assessment for manual wheelchair users have been made [8-12]. However, MBI and Functional Independence Measure (FIM) are used most widely [13,14]. Although MBI and FIM can assess basic ADL and mobility of diverse patient population, these tools are not specific for EPIOC users. A lower score is given to wheelchair ambulation [15]. To our knowledge, consented evaluating tools that focus on EPIOC user's ADL are not currently available. Thus, the aim of this paper is to discuss changes in ADL before and after provision of EPIOCs and problems of ADL evaluation tools currently being used for EPIOC users. This will provide preliminary data to develop ADL evaluation tool for EPIOC user.

\section{MATERIALS AND METHODS}

Retrospectively, a total of 92 EPIOC users who were prescribed EPIOC at Konkuk University Chungju Hospital from 2010 to 2012 were enrolled in this study. They have been using EPIOC for more than one year. All recruited EPIOC users were invited to the hospital. Face to face evaluation was conducted to increase the reliability of physical exam and survey. A total of 18 users could not visit hospital due to personal affairs. Four users declined to participate. Further exclusion criteria were not necessary for the remaining 70 users because all of them had enough cognitive function to communicate with favorable medical conditions. Through reviewing previous medical records, MBI before provision of EPIOCs and other medical conditions (history, diagnosis, the degree and type of disability, manual muscle test, range of motion, etc.) were available. FIM had not been used in the present hospital. Therefore, FIM score before provision of EPIOC could not be obtained. At the visitation, MBI, a questionnaire, and a general physical examination were 
conducted. Three other experienced physicians evaluated MBI and FIM scores separately. The averages of scores were used.

Because each tool has a different scale, FIM scores were compared to MBI after converting the measured score to percentage of perfect score. FIM included 13 motor items and 5 cognitive items, each item being graded 1 to 7 points. MBI contained 10 items, each item being graded 0 to 15 points. To convert the motor FIM score to percentage of perfect score, the minimum score 13 was set to $0 \%$ and the maximum score 91 was set to $100 \%$. The measured score was then calculated to percentage. The total FIM score (minimum score 18 to $0 \%$ and maximum score 126 to $100 \%$ ) was converted to percentage by the same method.

The questionnaire was composed of 6 categories and 31 questions about general socioeconomic states, currently using state, helpfulness of EPIOCs in terms of social participation and occupational chances, psychiatric influences, self reported degrees of independency and barriers of using EPIOCs, which could not be obtained from medical records. The questions in each category are as follows: socio-economic state (the type of health insurance, monthly income, educational states, occupational states, accommodation, cohabitants, etc.), currently using states (using periods, type of EPIOC, the number of previous EPIOCs, the reason of changing EPIOC, daily using time/distance/purpose), social participation (social participation frequency, type of social activity, presence of leisure or sports activity, accessibility to public facilities), psychiatric influences (confidence, current psychiatric problems, helpfulness of EPIOC for refreshing), difficulties and barriers (tight space, uneven terrain, door management, street crossing, ramp, curb, transfer, dressing, picking up objects, etc.), self-reported independency (How independent I am on a EPIOC? Do you think you will have restriction to perform ADLs if you don't use EPIOC?). The survey was conducted for 5 months from January to May 2013 using the face to face methods. All users provided informed consents. The study protocol was approved by Institutional Review Board of the university hospital.

For statistical data analysis, SPSS ver. 12.0KO for Windows software (SPSS Inc., Chicago, IL, USA) was used. Paired t-test was performed to analyze differences of MBI between before and after provision of EPIOC. Indepen- dent t-test was performed to analyze differences between MBI and FIM. For the questionnaire, frequency analysis was performed. In the statistical analysis, a p-value less than 0.05 was considered statistically significant.

\section{RESULTS}

For the 70 patients who completed the survey, their mean age was $44.6 \pm 13.2$ years old. The 70 patients included 43 males and 27 females. Cerebral palsy patients were dominant $(n=22)$, followed by spinal cord injury patients $(n=19)$, stroke and traumatic brain injury patients ( $\mathrm{n}=18$ ). Regarding the question about occupational states, only two patients (2.8\%) had occupations. One had his own business, the other worked at a social welfare center (Table 1).

Before using EPIOC, the mean MBI was 61.26 \pm 4.47 . After using EPIOC, mean MBI was 62.50 \pm 5.01 , which was not significantly different from that before EPIOC. Among MBI categories, there were no significant differences either except the wheelchair category. Before EPIOC was provided, wheelchair ambulation score was 2.85 \pm 1.43 . After EPIOC was provided, the wheelchair ambulation score was significantly increased to $4.73 \pm 0.45(\mathrm{p}<0.001)$ (Table 2).

Comparing MBI to FIM score (after being converted to percentage), the FIM score of $74.67 \pm 3.86$ was significantly higher than MBI score of $62.50 \pm 5.01(\mathrm{p}<0.001)$. However, motor FIM of $62.89 \pm 4.81$ was only slightly but not significantly higher than MBI ( $p>0.05$ ) (Table 2).

In the questionnaire, questions about social participation frequency, helpfulness of EPIOC to confidence,

Table 1. Demographic factors of participants

\begin{tabular}{lc}
\hline \multicolumn{1}{c}{ Characteristic } & No. (\%) \\
\hline Age (yr) & $44.6 \pm 13.2$ \\
\hline Sex (male:female) & $43: 27$ \\
Type of disability & \\
\hline Cerebral palsy & $22(31.4)$ \\
\hline Spinal cord injury & $19(27.1)$ \\
\hline Stroke \& traumatic brain injury & $18(25.7)$ \\
\hline Amputation & $4(5.7)$ \\
\hline Myopathy & $3(4.3)$ \\
\hline Arthropathy, motor neuron disease, etc. & $4(5.7)$ \\
\hline Occupation & $2(2.8)$ \\
\hline
\end{tabular}


Table 2. Mean score and comparison of converted score of MBI and FIM

\begin{tabular}{lcc}
\hline & $\begin{array}{c}\text { Converted score to } \\
\text { the perfect score }\end{array}$ & p-value \\
\hline MBI & & \\
$\begin{array}{l}\text { Before provision of EPIOC } \\
\text { After provision of EPIOC }\end{array}$ & $61.26 \pm 4.47$ & \\
$\begin{array}{l}\text { Wheelchair ambulation } \\
\text { (before) }\end{array}$ & $2.85 \pm 1.43$ & \\
$\begin{array}{l}\text { Wheelchair ambulation } \\
\text { (after) }\end{array}$ & $4.73 \pm 0.45$ & \\
FIM & $74.67 \pm 3.86$ & \\
$\begin{array}{l}\text { Motor FIM } \\
\text { After-before MBI }\end{array}$ & $62.89 \pm 4.81$ & \\
\hline $\begin{array}{l}\text { After-before wheelchair } \\
\text { ambulation }\end{array}$ & 1.24 & 0.127 \\
\hline $\begin{array}{l}\text { FIM-MBI } \\
\text { Motor FIM-MBI }\end{array}$ & 12.17 & $0.000^{*}$ \\
\hline
\end{tabular}

Values were presented as mean \pm standard deviation.

MBI, Modified Barthel Index; EPIOC, electric-powered indoor/outdoor chair; FIM, Functional Independence Measure.

${ }^{*} \mathrm{p}<0.001$.

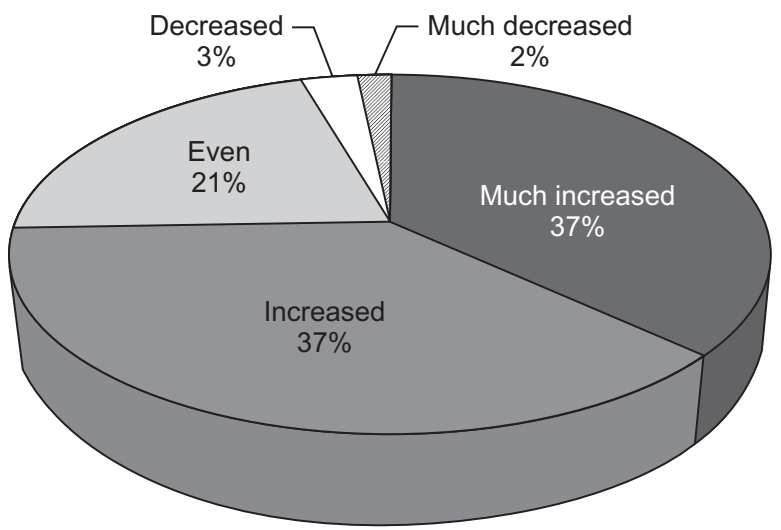

Fig. 1. The percentage of answer to the question "How much social participation was increased after using electric-powered indoor/outdoor chair (EPIOC)?".

refresh patients' emotion and self-reported degrees of independence were divided into five grades. For the question about how much social participation was increased after using EPIOC, 26 (37.1\%) and 26 (37.1\%) answered 'much increased' and 'increased,' respectively. A total of 52 patients (74.2\%) answered positive responses (Fig. 1).

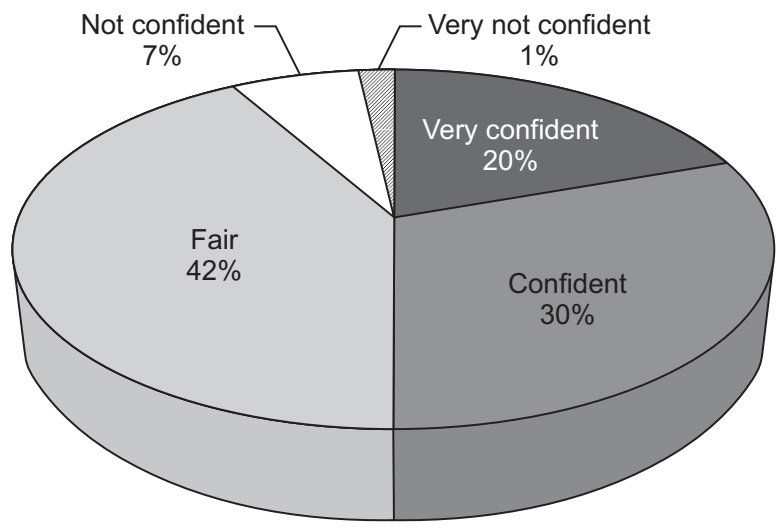

Fig. 2. The percentage of answer to the question "How confident you were in performing activity of daily living? Did you feel handicapped when you were on the electricpowered indoor/outdoor chair?".

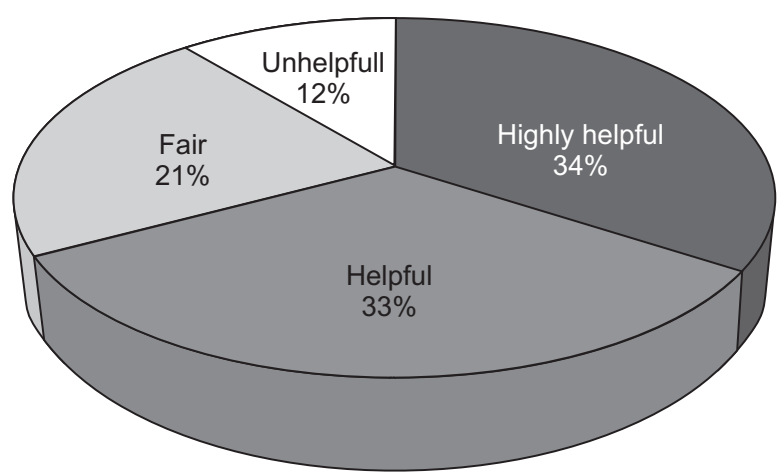

Fig. 3. The percentage of answer to the question "Are electric-powered indoor/outdoor chair helpful in the aspect of refreshing your mind?".

For the question about helpfulness of EPIOC to confidence ("How confident you were in performing activity of daily living? Did you feel handicapped when you were on the EPIOC?"), $14(20.0 \%)$ and $21(30.0 \%)$ answered 'very confident, not at all' and 'confident, not', respectively (Fig. 2 ). For the question about helpfulness of EPIOC in the aspect of refreshing mind, $24(34.3 \%)$ and $23(23.0 \%)$ answered 'highly helpful' and 'helpful', respectively. On the other hand, 15 (21.4\%) and 8 (11.4\%) answered 'fair' and 'unhelpful', respectively (Fig. 3). For self-reported independency in performing ADLs, $14(20.0 \%)$ and 35 (50.0\%) answered 'completely independent' and 'independent', respectively. Overall, a total of $70 \%$ answered positive responses. On the other hand, $15(21.4 \%)$ and $6(8.6 \%)$ answered 'substantially dependent' and 'dependent', respectively. No one answered 'completely dependent' (Fig. 


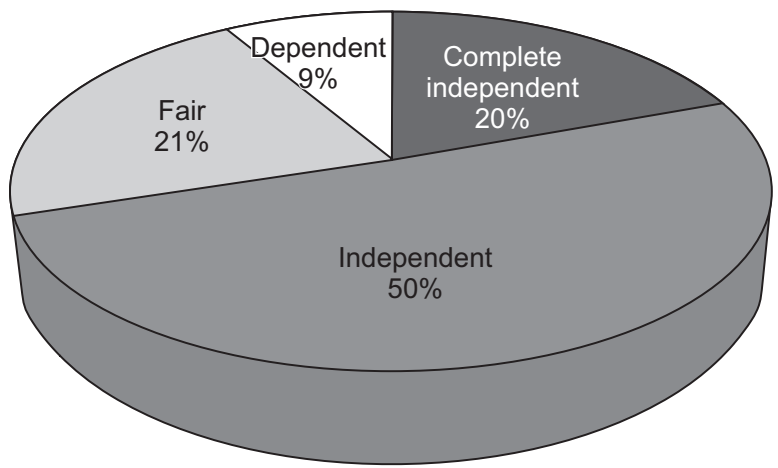

Fig. 4. The percentage of answer to the question "How independent you are in performing activities of daily living?".

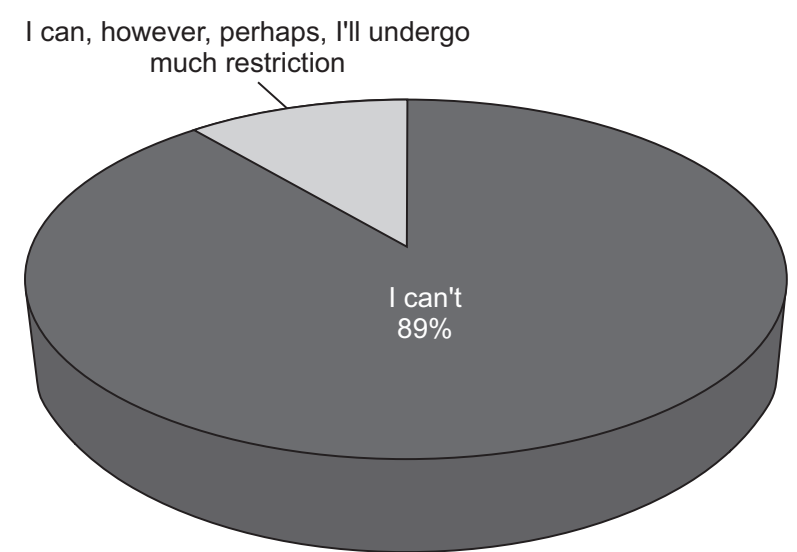

Fig. 5. The percentage of answer to the question "If you don't use electric-powered indoor/outdoor chair, can you perform outdoor activities?".

4). For question of "If you don't use EPIOC, can you perform outdoor activities?", 62 (88.6\%) answered 'I can't', whereas 8 (11.4\%) answered 'I can, however, perhaps, I'll undergo much restriction'. Nobody answered 'I can be the same as now' (Fig. 5).

For the question about problems associated with using EPIOCs, actual using problems (loading in a car, transfer, tight space and curb, incompatibility with architecture or furniture, threshold, etc.), insufficient infrastructures (e.g., road for EPIOC only, ramp, public transportation, etc.), EIPOC's own mechanical problems (e.g., low battery capacity, repair service, recurrent breakdown), and climate conditions remained as dominant complaints (Table 3).
Table 3. Difficulties and barriers to ambulation of EPIOCs

\begin{tabular}{|c|c|}
\hline & No. (\%) \\
\hline \multicolumn{2}{|l|}{ Actually using EPIOC } \\
\hline Transfer & $39(55.7)$ \\
\hline Loading up and down in a car & $67(95.7)$ \\
\hline Tight space and curb & $32(45.7)$ \\
\hline Threshold & 27 (38.5) \\
\hline Incompatibility with architecture or furniture & $41(58.6)$ \\
\hline Weather condition & $51(72.8)$ \\
\hline \multicolumn{2}{|l|}{ Traffic accident } \\
\hline Concern about accident & $38(54.3)$ \\
\hline Absence of own insurance & $31(44.3)$ \\
\hline Crossing street & $17(24.3)$ \\
\hline \multicolumn{2}{|l|}{ Insufficient infrastructure } \\
\hline Absence of own driveway & $65(92.8)$ \\
\hline Absence of ramp, lift & $57(81.4)$ \\
\hline Public transportation & $59(84.3)$ \\
\hline \multicolumn{2}{|l|}{ EPIOC vehicle problem } \\
\hline Low battery & $48(68.6)$ \\
\hline Poor repair service & $61(87.1)$ \\
\hline Recurrent breakdown & $46(65.7)$ \\
\hline Difficulty to delicate control & $23(32.8)$ \\
\hline Inadequate light source & $19(27.1)$ \\
\hline
\end{tabular}

\section{DISCUSSION}

Before and after EPIOC was provided, the MBI score was not significantly different. However, the score of wheelchair ambulation category showed a significant increase. Through this result, it is reasonable to conclude that EPIOCs can improve users' ambulatory abilities. However, because the score of the wheelchair category was only five, its influences on the total MBI score was negligible. If the score of the wheelchair ambulation category was high, the result would be different. Although the ambulation using a wheelchair actually has many limitations, the score of five is too small compared to the score of fifteen of the ambulation category. Furthermore, in the present days, social facilities such as paved road, elevator, ramp, and lift enable more convenient wheelchair trip [16]. Development of EPIOC itself also allows users to travel more distance and control more easily. Among Wheelchair Users Functional Assessment (WUFA) which is a functional assessment measure for manual 
wheelchair users, at least five categories can be improved by using EPIOC, including uneven terrain, door management, street crossing, ramp, curb and reaching function [17].

Although items of MBI did not show significant differences except for the ambulation category, many patients emphasized the importance of transfer activities. Patients said that more independent transfer would allow much higher level of ADL performance. Many patients also complained about difficulties in loading EPIOC to a car because of its heavy weight and impossible folding. Patients needed help to transport EPIOC. They had substantial restrictions in long distance trips. Many patients underestimated delicate control. It should be considered as very important because it is closely related to accidents. Actually, most patients had experienced big and small accidents. Therefore, hand function and dexterity, which are not currently included in the routine ADL evaluation of EPIOC user, should be considered as important factor.

While motor FIM was not significantly differed from MBI, the FIM score was measured to be greater than MBI. This finding might have resulted from the fact that categories such as expression, social interaction, problem solving, and memory were measured to be near perfect scores. Participants of this survey were actually using EPIOC. All users' MMSE scores should be greater than 24 in order to get supports from National Health Insurance. Another reason that motor FIM was measured to be lower than FIM was because when grading score FIM, if one needs aid device, the score cannot over score 6 . Moreover, the score 6 can be obtained if one can perform activity completely independently with the device. In other cases, the score is lower [18]. Besides the above mentioned aspects, because one who can drive EPIOC is apt to preserve favorable hand functions, transfer ability, and other functions, the possibility of selection bias thereby cannot be excluded.

Similar to the present study, other researchers also demonstrated that a Barthel index could be derived from the motor items of the FIM which has a good agreement with the directly assessed Barthel score [19,20]. However, their conversion criteria can be applied only to the motor items of FIM. Therefore, the present study cannot help comparing the MBI with FIM by converting to percentage, which is a limitation of the present study.
For question regarding social participation frequency, positive respondents answered they were doing outdoor activities more than three times per week. Social activities consisted stroll, shopping, health service, and meeting friends, etc. EPIOC users were performing such activity mostly without the help of another person. Those activities may provide confidence to EPIOC users and show positive answers to the question "How confident you were in performing activity of daily living? Did you feel handicapped when you were on the EPIOC?". Like the preceding tendency, the question about refreshing emotion showed positive responses. In other literatures, depressed/distressed SCI subjects reported spending more hours in bed, fewer days out of house, and receiving more paid personal care assistance than other subjects [21]. Depressive symptomatology was inversely related to social integration and occupation [22]. Above mentioned results and literatures have a thread connection in that outside activities were correlated with not only emotional states but also overall quality of life of a handicapped person.

Lastly, taking occupational states into consideration is also recommended. In the present study, only 2 patients (2.8\%) had occupations. Currently, the low employment rate of the disabled is a social issue. Therefore, prescribing EPIOC to patients with occupations can be a helpful option for the disabled, although they might not be perfectly suitable for the current prescription criteria.

EPIOC users' self-reported independency showed relatively favorable results. It had discrepancy with that of MBI or FIM. The mean MBI score was about sixty, corresponding to moderate disability [15] and 3 (moderate)/6 of disability ratings from Act on Welfare of Persons with Disabilities. Of the participants, complete paraplegia existed, corresponding to 1 (severe)/ 6 of disability ratings from Act on Welfare of Persons with Disabilities. According to the present results, EPIOC users did not feel disability as handicap when they are performing ADLs with EPIOCs. EPIOC thereby are assumed playing successful role as an extension of the body for ambulation. Considering development of technology in supporting independent living within the community for physically disabled individuals $[23,24]$, assistive device will play important role in overcoming disability so that disabled persons can be more independent.

In conclusion, it is obvious that EPIOC has brought 
great enhancement in mobility function and quality of life to disabled persons. However, due to the lack of specific evaluation tools for EPIOC, there is a significant gap between ADL levels measured by physicians and actual ADL levels experienced by EPIOC users. Thus, it is necessary to develop evaluation tools specific for EPIOC that will integrate both physical functions and psychosocial as well as occupational aspects.

\section{CONFLICT OF INTEREST}

No potential conflict of interest relevant to this article was reported.

\section{REFERENCES}

1. Batavia AI. Of wheelchairs and managed care. Health Aff (Millwood) 1999;18:177-82.

2. Kaye HS, Kang T, LaPlante MP. Mobility device use in the United States. Washington, DC: National Institute on Disability and Rehabilitation Research, US Department of Education; 2000.

3. Hosseini SM, Oyster ML, Kirby RL, Harrington AL, Boninger ML. Manual wheelchair skills capacity predicts quality of life and community integration in persons with spinal cord injury. Arch Phys Med Rehabil 2012;93:2237-43.

4. Frank AO, Ward J, Orwell NJ, McCullagh C, Belcher M. Introduction of a new NHS electric-powered indoor/ outdoor chair (EPIOC) service: benefits, risks and implications for prescribers. Clin Rehabil 2000;14:66573.

5. Davies A, De Souza LH, Frank AO. Changes in the quality of life in severely disabled people following provision of powered indoor/outdoor chairs. Disabil Rehabil 2003;25:286-90.

6. Evans S, Neophytou C, de Souza L, Frank AO. Young people's experiences using electric powered indooroutdoor wheelchairs (EPIOCs): potential for enhancing users' development? Disabil Rehabil 2007;29:128194.

7. de Morton NA, Keating JL, Davidson M. Rasch analysis of the Barthel index in the assessment of hospitalized older patients after admission for an acute medical condition. Arch Phys Med Rehabil 2008;89:641-7.

8. Cress ME, Kinne S, Patrick DL, Maher E. Physical functional performance in persons using a manual wheelchair. J Orthop Sports Phys Ther 2002;32:104-13.

9. Kirby RL, Swuste J, Dupuis DJ, MacLeod DA, Monroe R. The Wheelchair Skills Test: a pilot study of a new outcome measure. Arch Phys Med Rehabil 2002;83:108.

10. Marino RJ, Goin JE. Development of a short-form quadriplegia index of function scale. Spinal Cord 1999;37:289-96.

11. Marino RJ, Shea JA, Stineman MG. The capabilities of upper extremity instrument: reliability and validity of a measure of functional limitation in tetraplegia. Arch Phys Med Rehabil 1998;79:1512-21.

12. Catz A, Itzkovich M, Agranov E, Ring H, Tamir A. SCIM: spinal cord independence measure: a new disability scale for patients with spinal cord lesions. Spinal Cord 1997;35:850-6.

13. Wilkin D, Hallam L, Doggett MA. Measures of need and outcome for primary health care. Br J Gen Pract 1992;42:262.

14. The Uniform Data System for Medical Rehabilitation; Center for Functional Assessment Research. Guide for use of the Uniform data set for medical rehabilitation. Buffalo, NY: State University of New York at Buffalo; 1990.

15. Shah S, Vanclay F, Cooper B. Improving the sensitivity of the Barthel Index for stroke rehabilitation. J Clin Epidemiol 1989;42:703-9.

16. Rosenberg DE, Huang DL, Simonovich SD, Belza B. Outdoor built environment barriers and facilitators to activity among midlife and older adults with mobility disabilities. Gerontologist 2013;53:268-79.

17. Stanley RK, Stafford DJ, Rasch E, Rodgers MM. Development of a functional assessment measure for manual wheelchair users. J Rehabil Res Dev 2003;40:301-7.

18. Granger CV, Hamilton BB, Keith RA, Zielezny M, Sherwin FS. Advances in functional assessment for medical rehabilitation. Top Geriatr Rehabil 1986;1:5974.

19. Nyein K, McMichael L, Turner-Stokes L. Can a Barthel score be derived from the FIM? Clin Rehabil 1999;13:56-63.

20. Turner-Stokes L, Williams H, Rose H, Harris S, Jackson D. Deriving a Barthel Index from the Northwick Park Dependency Scale and the Functional Independence Measure: are they equivalent? Clin Rehabil 
2010;24:1121-6.

21. Tate D, Forchheimer M, Maynard F, Dijkers M. Predicting depression and psychological distress in persons with spinal cord injury based on indicators of handicap. Am J Phys Med Rehabil 1994;73:175-83.

22. Fuhrer MJ, Rintala DH, Hart KA, Clearman R, Young ME. Depressive symptomatology in persons with spinal cord injury who reside in the community. Arch Phys Med Rehabil 1993;74:255-60.
23. Hobbs DA, Close JK, Downing AR, Reynolds KJ, Walker LT. Developing a national research and development centre in assistive technologies for independent living. Aust Health Rev 2009;33:152-60.

24. Adya M, Samant D, Scherer MJ, Killeen M, Morris MW. Assistive/rehabilitation technology, disability, and service delivery models. Cogn Process 2012;13 Suppl 1:S75-8. 